\title{
Synergy between microwave irradiation and heterogeneous catalysis in an environmentally friendly self-condensation of hydroxybenzene derivatives
}

\section{Victoria Gómez*, Andrés Moreno, Ester Vázquez, Antonio de la Hoz,* Ana I. Aranda, and Ángel Díaz-Ortiz}

Facultad de Química, Universidad de Castilla-La Mancha, Campus Universitario, 13071

Ciudad Real, Spain

E-mail: Antonio.Hoz@uclm.es

Dedicated to Prof. Benito Alcaide on the occasion of his $60^{\text {th }}$ birthday

\begin{abstract}
Self-condensation of 1,3,5-trihydroxybenzene and 3,5-dimethoxyphenol using solid acid catalysts and microwave irradiation produces polyhydroxy-substituted biphenyl derivatives in moderate to good yields. Condensation of 1,3,5-trihydroxybenzene with $p$-benzoquinone gives 2,2'-dihydroxybiphenyl derivatives in good yields. On using classical heating these reactions do not occur or afford only traces of the desired products.
\end{abstract}

Keywords: Solid acid catalyst, supported catalyst, microwave, self-condensation, solvent-free

\section{Introduction}

Microwave irradiation is an unconventional energy source whose utility in synthetic organic chemistry has been increasingly recognized in recent years. ${ }^{1}$ On the other hand, solvent-free conditions are especially suitable for microwave activation and several advantages are evident in this approach. ${ }^{2}$ In the absence of solvent the irradiation is absorbed directly by the reagents, so the effect of microwaves is more marked. Moreover, solid supports can be used efficiently; many mineral oxides are poor conductors of heat whereas they absorb microwave irradiation very efficiently, ${ }^{3}$ a situation that produces a real benefit for supported reactions induced by microwaves. In this respect, microwave irradiation has been applied with success to several kinds of reactions. The rapid heating induced by microwave irradiation leads to the formation of the products under mild reaction conditions and with short reaction times. 
Interest in the chemistry of biphenyls is continually expanding. The biaryl moiety is found in a range of pharmaceuticals, natural products, agrochemicals, ligands, conducting polymers, liquid crystals and advanced materials. ${ }^{4}$

A well established method for the preparation of biphenyl compounds is the oxidative coupling of phenols. ${ }^{5}$ Oxidative coupling of phenols often gives low yields of the desired products and/or suffers from disadvantages due to the insolubility of the oxidant or phenol and difficulties in separating inorganic and organic products. In addition, transition metal-catalyzed cross-coupling reactions of aryl halides or equivalents with organometallic reagents is also a common method for the synthesis of these compounds. ${ }^{6}$ This procedure has several disadvantages such as reagent toxicity, air-sensitivity, low reactivity and long reaction times.

Diaryl ether moieties are known to be present in a variety of natural products and biologically interesting compounds ${ }^{7}$ such as antibiotics and important commercial polymers. ${ }^{8}$ As a consequence, there is a strong incentive for the synthesis of such systems. The Ullmann ether synthesis ${ }^{9}$ has been extensively used for the formation of diaryl ethers. ${ }^{10,11}$ However, the harsh reaction conditions $\left(125-220^{\circ} \mathrm{C}\right.$ in neat phenol or solvents such as pyridine, collidine or DMF), the usual requirement for stoichiometric (or greater) quantities of the copper complex and the fact that non-activated aryl halides usually react in low yields are all factors that have limited the utility of this reaction. ${ }^{10}$ Recent efforts to develop procedures that are applicable to more complex synthetic intermediates have found only limited success ${ }^{11 a, 12}$ or require the use of an activating group or the use of more complicated reaction mixtures. ${ }^{13}$

Conventional catalysts are required in a large excess and they contribute to increase environmental pollution. Consequently, there is a need for efficient and heterogeneous catalytic methods for this reaction involving inexpensive, easily handled and non-polluting acid catalysts; in this respect, zeolites, clays, modified-silica and sulfonic acid resins would result in simplified product recovery and minimization of undesirable waste streams.

The main objective of this paper is to show the synthetic utility of environmentally benign techniques (microwave irradiation, solvent-free reactions and solid acids) in organic synthesis in order to exemplify the synergy between them and simplify the experimental procedure for the formation of biaryl and diaryl ether derivatives. For these reasons we focused our efforts on developing a rapid, microwave-assisted condensation of hydroxybenzene derivatives utilizing solid acid catalysts - in particular sulfonic acid resins, clays and silica-modified Lewis acid catalysts. The aim was to achieve a reduction in the reaction times as well as to design an environmentally benign procedure that avoids the use of the polluting homogeneous catalyst commonly used.

\section{Results and Discussion}

The sulfonic acid resin and the clays employed were Dowex $(50 \times 8 \times 400)$ and Montmorillonite K10 and KSF, respectively. The silica-supported Lewis acid catalysts used for some of these 
reactions were obtained by treatment of silica with $\mathrm{ZnCl}_{2}[\mathrm{Si}(\mathrm{Zn})],{ }^{14} \mathrm{Et}_{2} \mathrm{AlCl}[\mathrm{Si}(\mathrm{Al})]^{15}$ or $\mathrm{TiCl}_{4}$ $[\mathrm{Si}(\mathrm{Ti})] \cdot{ }^{15}$ In the present paper a comparative study of the influence of the catalyst on yield will be discussed.

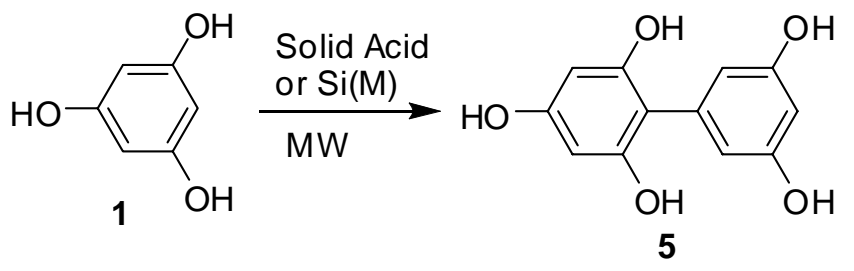

$\mathrm{M}=\mathrm{Zn}, \mathrm{Al}, \mathrm{Ti}$

Scheme 1. Self-condensation of 1,3,5-trihydroxybenzene.

Table 1. Condensation of mono-, di- and trihydroxybenzene derivatives using solid acid catalysts and microwave irradiation

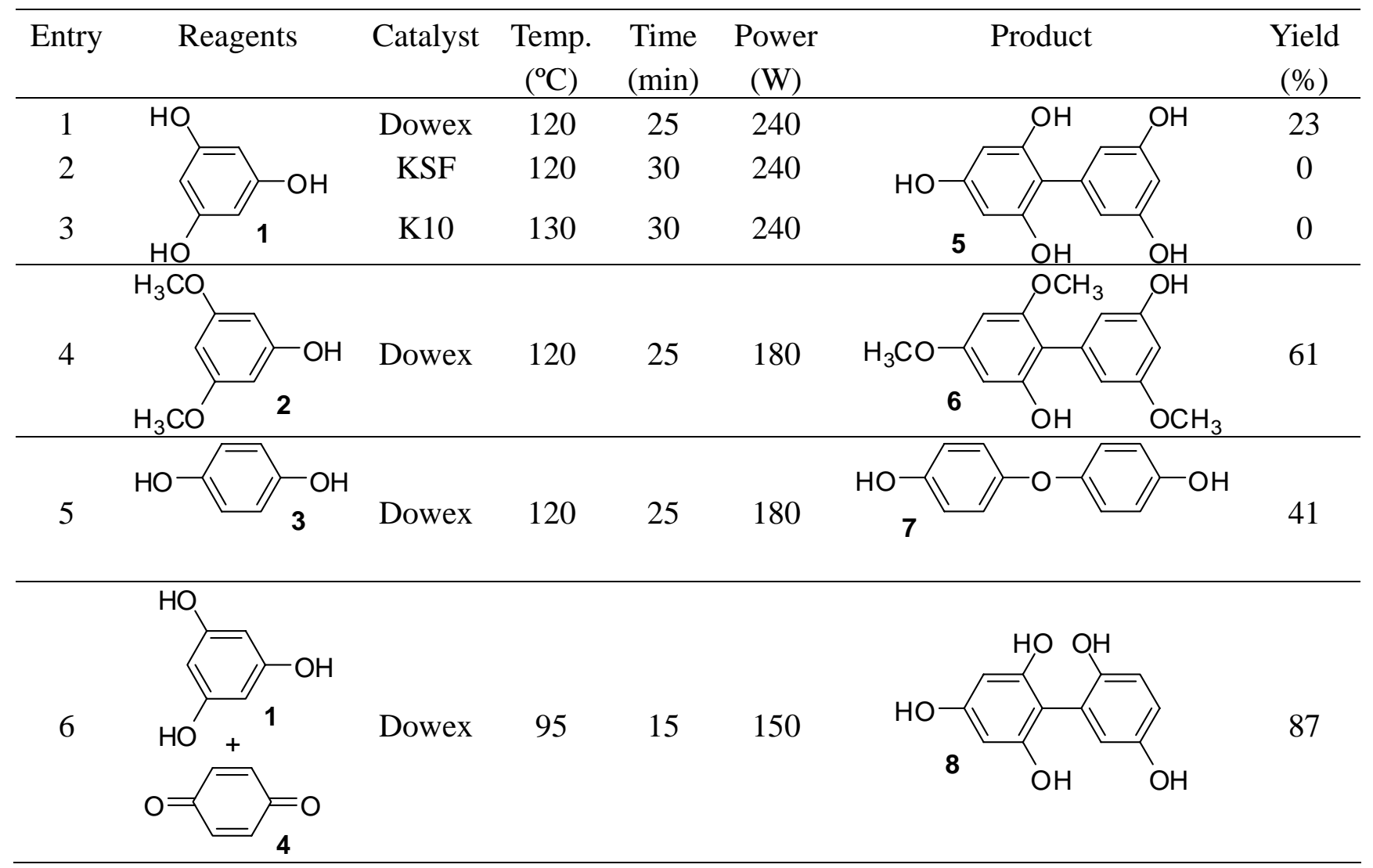

Reactions were performed in the absence of solvent and the reaction conditions were optimized to obtain the best yield. The results of the study into the synthesis of biphenyl derivatives by microwave irradiation using solid acid catalysts are shown in Table 1 . The nature of the catalyst was found, in some cases, to have a spectacular effect on yields (Table 1). 
It was found that hydroxybenzene derivatives $\mathbf{1}$ and $\mathbf{2}$ dimerize under microwave irradiation within 25-30 min to afford biphenyls 5 and 6, respectively (Table 1). Dimerization requires an activated phenol and a leaving group meta to the hydroxy group. Yields are higher on increasing the electron-donating nature of substituents (entry 1 vs entry 4). It should also be considered that dimerization of compound $\mathbf{2}$ is regioselective and produces compound $\mathbf{6}$ exclusively; nucleophilic attack occurs in para position of a methoxy group (not the hydroxy group) of the nucleophile and with substitution of a methoxy group (not the hydroxy group) of the electrophile (Scheme 2).

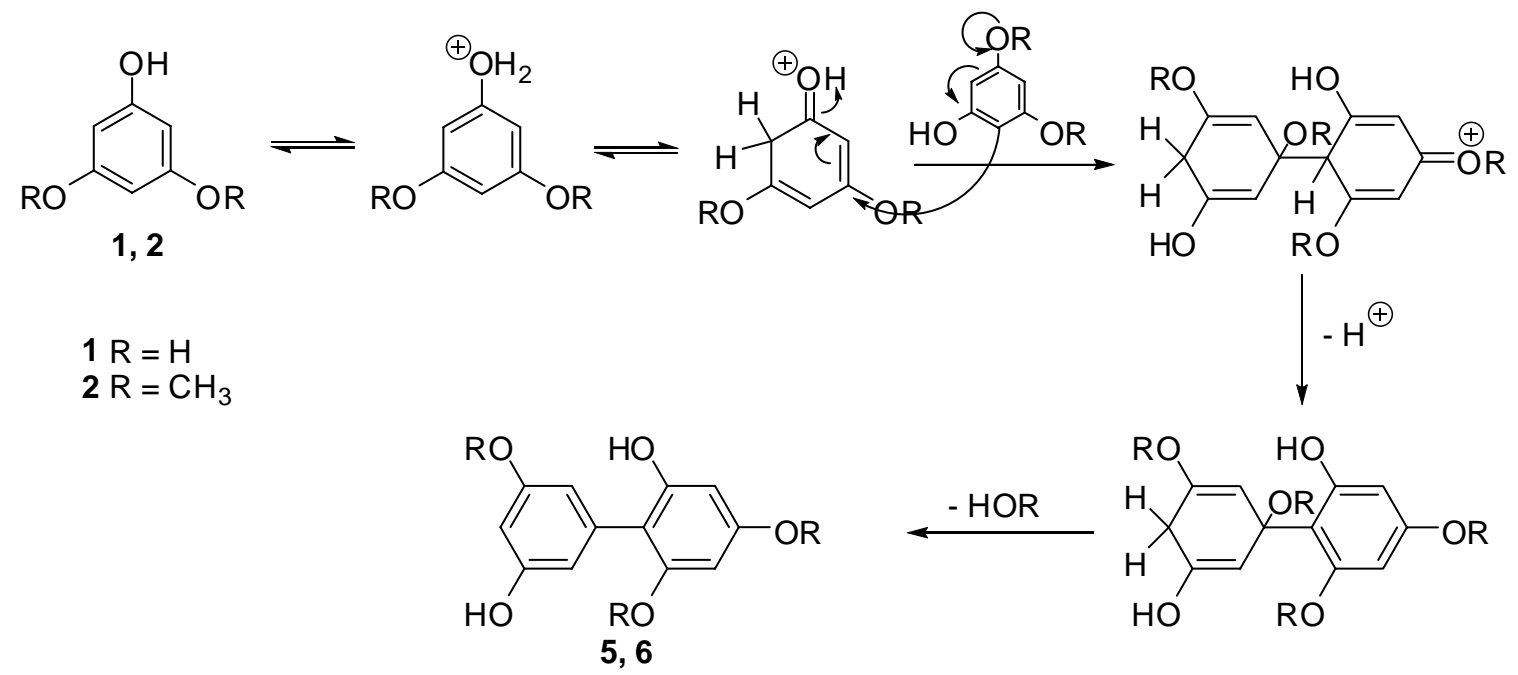

Scheme 2. Proposed mechanism for the self-condensation of 1,3,5-trihydroxybenzene 1 and 3,5dimethoxyphenol 2.

Self-condensation of hydroquinone (3) showed that even less reactive hydroxyphenyl derivatives dimerize under these conditions, albeit to give moderate yields (entry 5). The absence of one activating group reduces the nucleophilic character of the ring carbon atoms and reaction occurs by nucleophilic attack by oxygen. This enabled 4,4'-oxy-diphenol (7) to be obtained, showing that this could be a very simple procedure for the preparation of diaryl ethers from phenols.

The introduction of electron-donating groups increases the nucleophilicity of the aromatic compound, which in turn becomes a poor electrophile. In this respect, the addition of a good electrophile such as $p$-benzoquinone (4) produced a very good yield of the cross-coupling product 8 (entry 6).

Attempts to perform the coupling reaction with acidic clays (Montmorillonite K10 and KSF) as solid acids proved unsuccessful (entries 2 and 3 ).

The process described here, owing to its procedural simplicity and the use of readily available chemicals, appears to be a promising and useful route to a variety of polyhydroxy- 
substituted biphenyl and diaryl ethers. These findings demonstrate the potential of using solid acids.

We have used silica-supported Lewis acids as catalysts as acid catalysts in this reaction. We have previously used these catalyst with success in the Diels-Alder cycloaddition furan derivatives in solvent-free conditions and under microwave irradiation. ${ }^{16}$ The results obtained with these catalysts in the self-condensation of 1,3,5-trihydroxybenzene (1) are shown in Table 2.

Table 2. Self-condensation of 1,3,5-trihydroxybenzene (1).

\begin{tabular}{cccc}
\hline Entry & Solid Support & Reaction conditions & Yield (\%) 5 \\
\hline 1 & $\mathrm{Si}(\mathrm{Zn})$ & $120^{\circ} \mathrm{C} 25 \mathrm{~min} .240 \mathrm{~W}$ & 27 \\
2 & $\mathrm{Si}(\mathrm{Al})$ & $120^{\circ} \mathrm{C} 25 \mathrm{~min} .240 \mathrm{~W}$ & 47 \\
3 & $\mathrm{Si}(\mathrm{Ti})$ & $120^{\circ} \mathrm{C} 25 \mathrm{~min} .240 \mathrm{~W}$ & 51 \\
4 & $\mathrm{SiO}_{2}$ & $120^{\circ} \mathrm{C} 25 \mathrm{~min} .240 \mathrm{~W}$ & 0 \\
5 & $\mathrm{Si} \mathrm{(Ti)}$ & $120^{\circ} \mathrm{C} 25$ min. & 0 \\
\hline
\end{tabular}

${ }^{\text {a }}$ Conventional heating

It can be seen from the results in Table 2 that the nature of the silica-supported catalyst has a spectacular effect on the yield. Yields of compound $\mathbf{5}$ are higher on using the Lewis acid solids as catalysts. The use of Si(Ti) gives the best results and the polyhydroxybiphenyl derivative was obtained in moderate yield (see Table 2, entry 3 versus entry 1 and 2). It is remarkable that the use of $\mathrm{SiO}_{2}$ (Table 2, entry 4) does not promote any reaction at all. This result shows the importance of the catalytic activity of the metal.

These results can be explained in terms of the different acid characteristics of the catalyst $\mathrm{Si}(\mathrm{Zn})$ is a pure Lewis acid while $\mathrm{Si}(\mathrm{Al})$ and $\mathrm{Si}(\mathrm{Ti})$ have Lewis/Brönsted acid area ratios ${ }^{17}$ of 5.3 and 4.4, respectively. The mechanism proposed for the reaction is an aromatic electrophilic substitution in which Lewis acidity is not necessary. Microwave irradiation plays an important role in this process and the advantage of using microwave irradiation is not exclusively an acceleration of the reaction. Indeed, when all these reactions (with both types of catalyst) were performed using classical heating in an oil bath under comparable reaction conditions (time and temperature) the biphenyl product was not formed (for instance see Table 2, entry 3 vs. entry 5) even using longer reaction times.

However, the use of $\mathrm{Si}(\mathrm{Ti})$ for the preparation of biphenol derivatives $\mathbf{6}$ and $\mathbf{8}$ and diarylether 7 was always unsuccessful and no reaction took place in a wide variety of reaction conditions. 


\section{Conclusions}

In conclusion, the synthesis of a range of polysubstituted biphenyl derivatives has been achieved using solid acids or heterogeneous catalysis under microwave irradiation in solvent-free conditions.

The products are easily prepared in a single step by the action of Dowex or $\mathrm{Si}(\mathrm{Ti})$. A variety of polyhydroxy biphenyl derivatives can be synthesized by selecting the appropriate reactants. This method represents a simple and useful alternative for the preparation of some polyhydroxy biphenyl derivatives or diaryl ethers whose synthesis is difficult by other methods. In control experiments, reaction was not observed without microwave irradiation and thermal activation also proved inefficient.

Further work is in progress to establish the precise mechanism of this self-condensation in order to explain the observed reaction.

\section{Experimental Section}

General Procedures. Reactions under microwave irradiation were performed in a focused Prolabo MX350 microwave reactor. Temperature under microwave irradiation was measured with an IR pyrometer. Incident power and reaction temperature were controlled using especially designed software (PACAM-MPX-2). Reactions carried out using thermal heating were performed in an oil bath under similar conditions of temperature and time as the microwave reactions. Temperature under conventional heating was determined with a thermocouple submerged in the reaction mixture and previously calibrated with the IR pyrometer with a blank reaction.

All compounds were characterized by analytical methods and ${ }^{1} \mathrm{H}$ and ${ }^{13} \mathrm{C}$ NMR spectroscopy, using one- and two-dimensional techniques. The new compounds exhibit NMR spectra consistent with their structures and gave satisfactory molecular weight determinations (mass spectrometry). Melting points were determined using a Gallenkamp melting point apparatus and are uncorrected. NMR spectra were recorded on a Varian Unity 300 spectrometer with TMS as the internal standard and operating at $299.98 \mathrm{MHz}$ for ${ }^{1} \mathrm{H}$ and $75.423 \mathrm{MHz}$ for ${ }^{13} \mathrm{C}$. The mass spectra were recorded on a Waters GCT Mass Spectrometer and a VG AutoSpec apparatus using electron impact at $70 \mathrm{eV}$. Determination of exact mass was carried out with polyethylene glycol as the internal standard. Flash column chromatography was performed on silica gel 60 (Merck, 230-400 mesh).

Phenols (1-3) and benzoquinone (4) are commercially available chemicals and were purchased from Sigma-Aldrich and used without further purification. Compounds $\mathbf{5}$ and $\mathbf{7}$ showed to be identical to the commercially available.

Modified Lewis acids were obtained by treating silica gel with $1 \mathrm{M}$ solutions of $\mathrm{ZnCl}_{2}, \mathrm{AlEt}_{2} \mathrm{Cl}$ or $\mathrm{TiCl}_{4}$ following the previously described method. ${ }^{14,15}$ The silica contained $1.5 \mathrm{mmol}$ of $\mathrm{Zn} \mathrm{g}^{-1}$, 
$1.4 \mathrm{mmol}$ of $\mathrm{Al} \mathrm{g}^{-1}$ and $1.2 \mathrm{mmol}$ of $\mathrm{Ti}^{-1}$, respectively, as determined by plasma emission spectroscopy. For the $\mathrm{Si}(\mathrm{Zn})$ catalyst, activation for $2 \mathrm{~h}$ at $150{ }^{\circ} \mathrm{C}$ under vacuum was necessary before use. Reagents were supported on the catalysts by dissolving the mixture in $5 \mathrm{~mL}$ of diethyl ether followed by evaporation of the solvent.

\section{General procedure}

Phenols 1-3 (10 mmol) or a mixture of 1,3,5-trihydroxyphenol (1) (5 mmol) and p-benzoquinone (4) (5 mmol) supported on a solid acid support ( $1 \mathrm{~g}$ ) was exposed to microwave irradiation for the time and power indicated in Table 1. For isolation of the compounds, the solid support was removed by extraction with acetone. After solvent evaporation, products were purified by column chromatography on silica gel (hexane/AcOEt 2:1) or sublimation for compound 7. Yields were determined by ${ }^{1} \mathrm{H}$ NMR spectroscopy using the following internal standards: maleic anhydride ( $\delta=7.45 \mathrm{ppm}$ ) for entries $1-3$ in Table 1 and all entries in Table 2, succinic anhydride ( $\delta=2.9 \mathrm{ppm}$ ) for entry 4 in Table 1 and dichloroethane $(\delta=3.9 \mathrm{ppm})$ for entries 5 and 6 in Table 1. It should be remarked that for the reactions in entries 4 and 6 (Table 1 ) the isolated yields show differences of between 4 and $7 \%$ less than the calculated yields using the corresponding internal standard above indicated, thus demonstrating the accuracy of this method.

Biphenyl-2,3',4,5',6-pentol (5). ${ }^{18} \mathrm{mp}=216-218^{\circ} \mathrm{C}$ (from water). ${ }^{1} \mathrm{H}$ NMR (DMSO-d 6 ) $\delta 8.9$ (s, $1 \mathrm{H}, 4-\mathrm{OH}$ ), 8.89 (S, 2H, 2-OH and 6-OH), 8.72 (s, 2H, 3'-OH and 5'-OH), 6.09 (d, J= $2.0 \mathrm{~Hz}$, $2 \mathrm{H}, 2^{\prime}-\mathrm{H}$ and 6'-H), $6.02\left(\mathrm{t}, J=2.0 \mathrm{~Hz}, 1 \mathrm{H}, 4^{\prime}-\mathrm{H}\right), 5.83(\mathrm{~s}, 2 \mathrm{H}, 3-\mathrm{H}$ and $5-\mathrm{H}) .{ }^{13} \mathrm{C}$ NMR $\left(\mathrm{DMSO}_{6}\right.$ ) $\delta$ 157.0, 156.0 (2-C, 6-C, 5'-C, 3'-C), 156.8 (4-C), 136.5, 108.0 (1'-C and 1-C), 109.5 (2 $-\mathrm{C}$ and 6'-C), 100.0 (4'-C), 94.0 (3-C and 5-C). HRMS calculated for $\mathrm{C}_{12} \mathrm{H}_{10} \mathrm{O}_{5}$ 234.0528, found 234.0436 .

4,5',6-Trimethoxybiphenyl-2,3'-diol (6). Yellow oil, bp $225^{\circ} \mathrm{C}$ (oven temperature) / 0.1 mbar in a Kugelrohr apparatus. ${ }^{1} \mathrm{H}$ NMR $\left(\mathrm{CDCl}_{3}\right) \delta 6.45$ (dd, $J=2.1$ and $\left.1.2 \mathrm{~Hz}, 1 \mathrm{H}, 2 \mathrm{H}\right), 6.40$ (dd, $J$ $=2.1$ and $\left.2.4 \mathrm{~Hz}, 1 \mathrm{H}, 4^{\prime}-\mathrm{H}\right), 6.38$ (dd, $J=1.2$ and $\left.2.4 \mathrm{~Hz}, 1 \mathrm{H}, 6^{\prime}-\mathrm{H}\right), 6.21$ (d, $J=2.3 \mathrm{~Hz}, 1 \mathrm{H}, 3-$ H), 6.14 (d, $J=2.3 \mathrm{~Hz}, 1 \mathrm{H}, 5-\mathrm{H}), 5.43$ (bs, 1H, 2-OH), 5.34 (s, 1H, 5'-OH), 3.81 (s, 3H, 4$\left.\mathrm{OCH}_{3}\right), 3.77$ (s, 3H, 3'- $\left.\mathrm{OCH}_{3}\right), 3.70\left(\mathrm{~s}, 3 \mathrm{H}, 6-\mathrm{OCH}_{3}\right) .{ }^{13} \mathrm{C} \mathrm{NMR}\left(\mathrm{CDCl}_{3}\right) \delta 161.5,160.8,157.93$, 154.2 (4-C, 6-C, 5'-C, 3'-C and 2-C), 134.5 (1'-C), 110.3 (6'-C), 109.6 (1-C), 108.9 (2'-C), 101.2 (4'-C), 92.8 (3-C), 91.7 (5-C), 55.4 (6-C), 55.3 (4-C and 3'-C). HRMS calculated for $\mathrm{C}_{15} \mathrm{H}_{16} \mathrm{O}_{5}$ 276.0098, found 276.0057.

4,4'-Oxy-diphenol (7). Mp 164-167 ${ }^{\circ} \mathrm{C}$ (sublimation). ${ }^{1} \mathrm{H}$ NMR (DMSO-d 6 ) $\delta 9.2$ (bs, 2H, 4-OH and 4'-OH), 6.75 (m, 4H, 2-H, 6-H, 2'-H and 6'-H), 6.70 (m, 4H, 3-H, 5-H, 3'-H and 5'-H). ${ }^{13} \mathrm{C}$ NMR (DMSO- $\mathrm{d}_{6}$ ) $\delta$ 152.9, (1-C and 1'-C), 149.9 (4-C and 4'-C), 120.0 (2-C, 6-C, 2'-C and 6'-C), 117.0 (3-C, 5-C, 3'-C and 5'-C). HRMS calculated for $\mathrm{C}_{12} \mathrm{H}_{10} \mathrm{O}_{3}$ 202.0630, found 202.0620.

Biphenyl-2,2',4,5',6-pentol (8). Mp 183-184.5 ${ }^{\circ} \mathrm{C}$ (from acetone/dichloromethane). ${ }^{1} \mathrm{H}$ NMR (DMSO-d 6 ) $\delta 8.98$ (s, 1H, 4-OH), 8.72 (bs, 2H, 2-OH and 6-OH), 8.48 (s, 1H, 5'-OH), 7.85 (bs, 1H, 2'-OH), 6.6 (dd, $J=8.6$ and $1.5 \mathrm{~Hz}, 1 \mathrm{H}, 3$ '-H), 6.45 (dd, $J=8.6$ and $1.5 \mathrm{~Hz}, 1 \mathrm{H}, 4 '-\mathrm{H}$ ), 6.44 (t, $1.5 \mathrm{~Hz}, 1 \mathrm{H}, 6$ 6'-H), 5.85 (s, 2H, 3-H and 5-H). ${ }^{13} \mathrm{C}$ NMR (DMSO-d 6 ) $\delta 156.0$ (2-C and 6-C), 
119.0 (6'-C), 116.0 (3'-C), 114.0 (4'-C), 94.9 (5-C and 3-C), 157.8, 149.3, 147.7 (5'-C, 2'-C and 4-C), 123.0, 104.8 (1'-C and 1-C). HRMS calculated for $\mathrm{C}_{12} \mathrm{H}_{10} \mathrm{O}_{5} 234.0528$, found 234.0536.

\section{Acknowledgements}

Financial support from the DGICYT of Spain through project CTQ2007-60037/BQU and from the Consejería de Ciencia y Tecnología JCCM through projects PBI-06-0020 and PCI-08-0040 is gratefully acknowledged. M.V.G. acknowledges the European Union for a Marie Curie Reintegration Grant.

\section{References}

1. (a) Mingos, D. P. M.; Whittaker, A. G. Microwave Dielectric Heating Effects in Chemical Synthesis in Chemistry under Extreme or Non-Classical Conditions; Eldik, R.; Hubbard, C. D. Eds.; Wiley: Weinheim; 1997. (b) Microwaves in Organic Synthesis; Loupy, A., Ed.; Wiley-VCH: Weinhein; 2002. (c) Microwave-Assisted Organic Synthesis; Lidström, P., Tierney, J. P. Eds., Blackwell Scientific: Oxford; 2004. (d) Kappe, C. O. Angew. Chem. Int. Ed. 2004, 43, 6250. (e) Kappe, C. O.; Stadler, A. Microwaves in Organic and Medicinal Chemistry; Wiley-VCH: Weinheim; 2005.

2. (a) Loupy, A.; Petit, A.; Hamelin, J.; Texier-Boullet, F.; Jacquault, P.; Mathé, D. Synthesis 1998, 1213. (b) Varma, R. S. Green Chem. 1999, 1, 43. (c) Varma, R. S. Green Chem.Let. Rev. 2007, 1, 37.

3. Loupy, A.; Bram, G.; Sansoulet, J. New J. Chem. 1992, 16, 233.

4. For reviews see: (a) Snieckus, V. Chem. Rev. 1990, 90, 879. (b) Stanforth, S. P. Tetrahedron 1998, 54, 263. (c) Hassan, J.; Sévignon, M.; Gozzi, C.; Schulz, E.; Lemaire, M. Chem. Rev. 2002, 102, 1359.

5. (a) Kaeding, W. W. J. Org. Chem. 1962, 28, 1063. (b) Dewar, M. J. S.; Nakaya, T. J. Am. Chem. Soc. 1968, 90, 7134. (c) Villemin. D.; Sauvaget. F. Synlett 1994, 6, 435. (d) Sakamoto, T.; Yonehara, H.; Pac, C. J. Org. Chem. 1994, 59, 6859. (e) Kantam, M. L.; Santhi, P. L. Synth. Commun. 1996, 26, 3075. (f) Jana, S.; Pande, S.; Kumar Sinha, A.; Pal T. Inorg. Chem. 2008, 47, 5558.

6. (a) Trost, B. M.; Verhoeven, T. R. In Comprehensive Organometallic Chemistry; Wilkinson, G., Stone, F. G., Abel, E. W. Eds.; Pergamon: Oxford; 1982; Vol. 8, pp 799-938. (b) Heck, R. F. Palladium Reagents in Organic Syntheses; Academic Press: New York ; 1985. (c) Tsuji, J. Synthesis 1990, 739. (d) Tsuji, J. Palladium Reagents and Catalysts; Wiley: Chichester; 1995. (e) Burgos, C. H.; Barder, T. E.; Huang, X.; Buchwald, S. L. Angew. Chem. Int. Ed. 2006, 45, 4321. 
7. (a) Sano, S.; Ikai, K.; Kuroda, H.; Nakamura, T.; Obayashi, A.; Ezure, Y.; Enomoto, H. J. Antibiot. 1986, 39, 1674. (b) Kase, H.; Masami, K.; Yamada, K. J. Antibiot. 1987, 40, 450. (c) Itokama, H.; Takeya, K. Heterocycles 1993, 35, 1467. (d) Evans, D. A.; DeVries, K. M. In Glycopeptide Antibiotics, Drugs and the Pharmaceutical Sciences; Nagarajan, R., Ed.; Marcel Decker, Inc.: New York; 1994; Vol. 63, pp 63-104. (e) Sawyer, J. S.; Tetrahedron 2003, 59, 7859. (f) Evano, G.; Blanchard, N.; Toumi, M. Chem. Rev. 2008, 108, 3054.

8. (a) Atkinson, B. A. In Antibiotics in Laboratory Medicine; Lorian, V., Ed.; Williams and Wilkins: Baltimore; 1986; p 995. (b) Glycopeptide Antibiotics, Drugs and the Pharmaceuticals Sciences; Nagarajan, R., Ed.; Decker, Inc.: New York; 1994; Vol. 63. (c) Labadie, J. W.; Hedrick, J. L.; Ueda, M. Am. Chem. Soc. Symp. Ser. 1996, 624, 210.

9. Ullmann, F. Chem. Ber. 1904, 37, 853.

10. (a) Moroz, A. A.; Shvartsberg, M. S. Russ. Chem. Rev. 1974, 43, 679. (b) Lindley, J. Tetrahedron 1984, 40, 1433. (c) Hassan, J.; Sevignon, M.; Gozzi, C.; Schulz, C.; Lemaire, M. Chem. Rev. 2002, 102, 1359. (d) Frlan, R.; Kikely, D.; Synthesis 2006, 227.

11. (a) Carruthers, W. In Comprehensive Organometallics Chemistry; Wilkinson, G., Ed.; Pergamon Press: New York; 1982; Vol. 7, p 690. (b) Evans, D. A.; Ellman, J. A. J. Am. Chem. Soc. 1989, 111, 1063. (c) Boger, D. L.; Yohannes, D. J. Org. Chem. 1990, 55, 6000. (d) Boger, D. L.; Patane, M. A.; Zhou, J. J. Am. Chem. Soc. 1994, 116, 8544.

12. (a) Tomita, M.; Fujitami, K.; Aoyagi, Y. Chem. Pharm. Bull. 1965, 13, 1341. (b) Nogradi, M.; Vermes, B.; Kajiar-Peredy, M. Tetrahedron Lett. 1987, 28, 2899. (c) Boger, D. L.; Sakya, S. M.; Yohannes, D. J. Org. Chem. 1991, 56, 4204. (d) Boger, D. L.; Yohannes, D. Tetrahedron Lett. 1989, 30, 2053. (e) Jung, M. E.; Jachiet, D.; Rohloff, J. C. Tetrahedron Lett. 1989, 30, 4211.

13. For selected examples with ortho-activating groups, see: (a) Rozanel'skaya, N. A.; Stepanov, B. I. Zhur. Obshch. Khim. 1961, 31, 758. (b) Pellon, R. F.; Carrasco, R.; Milian, V.; Rodes, L. Synth. Commun. 1995, 25, 1077 and references cited therein. (c) Nicolaou, K. C.; Boddy, C. N. C.; Natarajan, S.; Yue, T.-Y.; Li, H.; Brase, S.; Ramanjulu, J. M. J. Am. Chem. Soc. 1997, 119, 3421. (d) Kidwai, M.; Mishra N. K.; Bansal, V.; Kumar, A.; Mozumdar, S. Tetrahedron Lett. 2007, 48, 8883. (e) Jammi, S.; Sakthivel, S.; Rout, L.; Mukherjee, T.; Mandal, S.; Mitra, R.; Saha, P.; Punniyamurthy, T.; J. Org. Chem. 2009, 74, 1971.

14. Rhodes, C. N.; Brown, D. R. J. Chem. Soc., Faraday Trans. 1993, 89, 1387.

15. (a) Cativiela, C.; Fraile, J. M.; García, J. I.; Mayoral, J. A.; Pires, E.; Royo, A. J.; Figueras, F. Tetrahedron 1993, 43, 4073. (b) Cativiela, C.; Figueras, F.; García, J. I.; Mayoral, J. A.; Pires, E.; Royo, A. J. Tetrahedron: Asymmetry 1993, 4, 621.

16. (a) de la Hoz, A.; Díaz-Ortiz, A.; Fraile, J. M.; Gómez, M. V.; Mayoral, J. A.; Moreno, A.; Saiz, A.; Vazquez, E. Synlett 2001, 753. (b) Moreno, A.; Gómez, M. V.; Vázquez, E.; de la Hoz, A.; Díaz-Ortiz, A.; Prieto, P.; Mayoral, J. A.; Pires, E. Synlett 2004, 1259.

17. The modified silicas were characterized by IR spectroscopy. Pyridine adsorption-desorption experiments were carried out in order to determine the relative proportion of Lewis and Brönsted acidic sites. Thus, Lewis/Brönsted acid area ratios were determined by the integral 
areas of Lewis and Brönsted IR bands of pyridine adsorbed onto modified silicas previously described by Fraile, J. M.; García, J. I.; Mayoral, J. A.; Pires, E.; Salvatella, L.; Ten, M. J. Chem. Phys. B 1999, 103, 1664.

18. Riedl, V. W.; Imhof, F. Ann. 1955, 597, 153. 